\title{
Exotic or Erotic - Contrasting Images for Defining Destinations
}

\author{
Bruce Prideaux*, Jerome Agrusa, Jon G. Donlon and Chris Curran \\ James Cook University, PO Box 6811, Cairns, QLD 4870, Australia
}

\begin{abstract}
Sex and sexuality are powerful human emotions that have been exploited by the tourism industry to develop aspects of destination image. Where destinations have sought to exploit sex by use of the erotic as an appealing image, sex becomes a featured selling point and may inadvertently become more important than other elements of the destination's preferred image as a result of image capture where the preferred image is displaced by a less preferred image. This paper examines the potential for image confusion when the erotic is used alongside the exotic as part of destination image. In particular, Thailand's preferred image as an exotic destination and the nation's unofficial image as a location for erotic activities are considered. Marketing implications are examined, as are potential measures that may be implemented to soften or even eliminate potentially negative impacts that are presently associated with Thailand's reputation as a center for sex tourism.
\end{abstract}

Key words: image, exotic, erotic, HIV/AIDS, sex tourism, Thailand

\section{Introduction}

"Exotic" and "erotic" are powerful words that convey equally powerful images, particularly in a touristic setting. "Exotic" embodies images of differentness in a place that is far removed from a person's normal physical and social reality and is normally only able to be experienced through the act of undertaking a journey. "Erotic", from eros, the Greek word for love, is defined in the Concise Oxford English
Dictionary (Pearsall, 2002) as "relating to or tending to arouse sexual desire or excitement" while eroticism is defined in the same reference as "sensual desire or excitement". Erotic is the embodiment of a range of sexual desires that, unlike the exotic, can be experienced in almost any setting, including the familiar surroundings of home with a long-term partner, with a total stranger, as a commercial transition, and in physical, pictorial, virtual or electronic forms. Travel need not be part of an erotic

\footnotetext{
*E-mail: b.prideaux@ug.edu.au
} 
experience. Oppermann (1998) noted that prostitution, both female and male, is common in many exotic destinations. Offered in combination, the ability to engage in erotic experiences in an exotic location has considerable appeal to some groups of travellers.

The rapid growth of GDP in many tourismgenerating countries allied with increased leisure time and the visual stimulus of the print and electronic media has created a demand for exotic as well as erotic travel experiences and created new opportunities for the provision of both exotic and erotic travel products and services. National poverty or prosperity appears to have little to do with the emergence of destinations that offer the exotic and/or the erotic as tourism images and products. For Asians, Europe is an exotic destination; quite different spiritually, materially and culturally from their own reality. Similarly, Asia is exotic to the Western mind with a material, social and spiritual culture that is not encountered in a European setting. In both Asia and Europe, sex industries have emerged to satisfy the demand for sexual experiences that offer the erotic in an exotic setting.

In this paper the term "erotic" is used as a substitute for the more commonly used term "sex tourism". Cohen (1971; 1993), Pruitt and La font (1995), Law (2000) and Oppermann (1998) have noted that in some circumstances participants in erotic activity while on holiday may go beyond the time-limited transaction that is characteristic of the commercial sex industry and enter into relationships that may last for several days or longer, that may or may not include a monetary transaction and may include an element of emotional engagement. Cohen (1982) described the situation where there was some form of emotional attachment as "opened-ended" prostitution. Arrangements of this nature have also been described as grey prostitution (Cohen, 1993) and indirect prostitution (ADVENT 1993). This paper examines the implications of using the erotic as a destination image and raises a range of issues that may emerge. Further, the paper discusses the difficulty of maintaining parallel destination images that promote the exotic as a trademark, yet retain the erotic as an unofficial though important market segment. The value of this analysis is that it attempts to articulate the issues involved in pursuing this form of dualism and highlights both the negatives and positives of attempting to develop the exotic but retaining the exotic as a promotional strategy, either in an official or unofficial form. Thailand was selected as a case study because elements of the nation's tourism industry deliberately use the exotic to attract visitors and because of its reputation as destination where sexual encounters may progress beyond the timelimited experience that is a feature of the commercial sex industry in many other destinations. In the Thai context both the exotic and erotic are built on authentic aspects of the host society; however, elements of the authentic have been heavily commodified to attract the tourist.

The term "exotic" is not explored in depth in this paper but is used in the context of offering a touristic space that is differentiated from the tourist's normal daily life space and experiences by differences in location, cuisine, culture, society and activity. In recent research the term "exotic" has been used in a different context, and Minca (2000, p. 392) for example describes exotic in terms of

tourist spaces (that) are very often structured hierarchically around one or more poles of attraction giving rise to more of less guided phenomena of specialization as well as core-periphery dynamics, 
largely emergent from an increasing stratification of demand.

As a consequence of these forces of mass tourism the pre-tourist localities, particularly in developing countries, are reformed into new spaces that conform to the current pattern of internationalized mass tourism in terms of structure, use of space, commodification of cuisine and attractions, often with only marginal concessions to the culture and heritage of the host society. In Cancun, Mexico for example, the transformation of the Mayan jungle into a clone Westernized beach destination is so complete that the exotic is little more than a thin veneer of restaurants offering "authentic" Mexican cooking, commodified Mayan motifs and souvenirs; and for some, day trips to Mayan archeological sites. Yet the visitor is given the impression that they are embarking on an exotic adventure but within the confines of their own experiences of cultural normality.

A number of researchers (Dann, 1977; LaPage and Cormier, 1977; Um and Compton, 1992; Chen and Hsu, 2000; Tapachai and Waryszak, 2000) have explored the significance of destination image as a factor in holiday purchase. In one of the first papers on the role of image LaPage and Cormier (1977) noted that it is often the image rather than factual information which leads to a travel purchase. Tourists often have limited knowledge of a destination (Um and Compton, 1992) leading to the circumstance where image becomes a substitute for more factual information. According to push and pull theory (Dann, 1977) pull factors are tied to tourists' perceived images of a destination. It is apparent that in the growing literature on destination image little consideration has been given to the type of circumstances occurring in Thailand where undesired image capture has occurred as the preferred image has, in part, been displaced by a less preferred image because of structural factors in the destination.

Investigations of the sex industry as a tourism resource have been undertaken by a number of authors including Cohen (1971, 1982, 1986, 1988, 1993), Graburn (1983) Oppermenn (1998), Ryan and Hall (2001), Clift and Carter (2000), Dahlas and Bras (1999), Pruitt and La Font (1995) and Agrusa and Prideaux (2002). As a consequence of these and other investigations, sex tourism has become a recognized field of tourism research and joins with the wider body of research into prostitution and commercial sex work found in the social science literature. Much of the scholarship related to the tourism aspects of the commercial sex industry was published in the 1990s although several significant books have been published in recent years including Ryan and Hall (2001) and Bauer and McKercher (2003). The types of encounter and the impact that such encounters have on the participants, including both the visitor and the host, have been examined by a number of researchers including Dahlas and Bras (1999) who reported on the role of entrepreneurs in holiday romance in Indonesia, Pruitt and La Font (1995) who examined romance tourism between hosts and guests in Jamaica, and Leheney (1995) who examined the impact of sex tourism on the political economy of parts of Asia.

In the literature the term "sex tourism" has been used to describe a wide range of commercial and other forms of sexual encounters between visitors and hosts; however, Oppermann (1998) questioned the use of the term "sex tourist", finding it simplistic and unable to adequately describe many of the sexual encounters that occur during periods of travel away from home. Examples of encounters described by Oppermann included the convention delegate who has a brief encounter with another delegate 
or who had an unplanned encounter with a commercial sex worker. Neither encounter may have been premeditated but under some definitions are classified as sex tourism. Other researchers have explored the impact of the commercial sex industry on the host and host community, with a number of studies focusing on Thailand (Cohen 1982, 1986, 1988, 1993, 1996; Phillip and Dann, 1998; Odzer, 1994).

The relationship between customers and prostitutes can change over time. Symanski (1981) suggested a relationship continuum commencing with a straightforward commercial exchange that may extend into a longer period of relationship such as a "travel companion" or even marriage (Thiemann 1989). Odzer (1994) contends that in Thailand the customer/prostitute relationship may turn into a savior/damsel-in-distress relationship where the customer may eventually marry the woman he first encountered in a Patpong bar. From a sociological view the relationships described by Symanski's (1981) continuum includes customers, hosts, gender issues, legality and corruption. While the relationship between travel and participating in sexual experiences has been extensively documented, there has been relatively little examination of the role such encounters of this nature have on national image and the motivation to travel to a specific destination.

\section{The Role of Sex in the Tourism Industry}

In the tourism industry sex is used both covertly and overtly as a promotional tool. In a discussion on the use of sex to market destinations Oppermann, McKinley and Chon (1998, p. 21) observed that images of tourism destinations "are the sum of ideas and beliefs about a destination". They further note that despite several decades of research into tourism destination image, the significance of sex as a variable has been ignored. Yet marketers often use idealized sexual images and information to sell destinations. Thus the words "sun", "sand" and "sex" may be used collectively to build an image of a destination as a "sun, sand and sex" destination or individually to describe a particular feature of a destination. In a more subtle approach, attractive and scantly dressed female (and increasingly male) bodies may be used to convey an image that is risque but not overtly hedonistic (Prideaux, 1995). The underlying message remains the same: an appeal to sexual fantasy. The use of images with a sexual connotation to attract tourists is not new, and as early as the 1920s promotional brochures for Hawaii produced by Pan Am showed images of bare-breasted native women beckoning tourists to visit Hawaii in an era when the normal female swimming costume was of a neck-to-knee design.

From a tourism viewpoint, sexual activity in destinations can be viewed from a number of perspectives, including between participants who travel together to a destination, participants who seek out temporary partners once at the destination, and commercial sexual services available in the destination. This paper considers only the latter where a commercial element is evident and as a consequence the destination develops a reputation or image of commercial erotic activities.

The structure and organization of the commercial sex industry can be described as either industrial or craft (Hubbard, 2003). In this sense the term "industrial prostitution" describes prostitution organized along industrial lines with investment in brothels, bars and similar establishments as well as organized distribution and marketing. Prostitution of this nature is very obvious and accessible, and a number of countries including Thailand 
support prostitution of this nature. "Craft prostitution" on the other hand implies a lower level of formal organization where the workers operate on an informal basis such as from the road or via adverts placed in the media. Hubbard (2003) for example reports on craft prostitution along highways in the border zones of Central America. A destination where craft prostitution is the main form of organization may have an image of the erotic, but it is buried behind other preferred images to the extent that experiences of the erotic must be actively sought out by potential consumers either along roadsides, in disguised premises or through the media.

In countries where prostitution is operated as a craft industry, self-employed prostitutes often seek out potential clients in areas frequented by tourists including bars and streets. Cuba, once famous for organized industrial prostitution in the pre-Castro era, outlawed prostitution after the revolution but in recent years many self-employed young women have entered the craft prostitution industry and approach foreign men for "dates". In the sense in which the word is used, a "date" is generally a commercial sexual encounter.

It is also possible to find destinations where there is evidence of industrial prostitution, which is partially hidden and operated as an organized though disguised industry, with sex workers camouflaged as massage therapists, social escorts or even hairdressers. The Vietnamese sex industry typifies this approach, with many beer halls operating as fronts for prostitution (Agrusa and Prideaux, 2002), while in China, bars and massage therapy practices may sometimes operate as fronts for forms of prostitution in areas frequented by domestic and international tourists.
In other destinations, less emphasis is given to camouflaging the sex industry, or at least some of its more obvious aspects, and elements of the sex industry have become semi-legitimized as mainstream tourism attractions, Amsterdam, Las Vegas and Kings Cross, Sydney are three of many such examples. At the other end of the spectrum, industrial prostitution may operate more openly, perhaps while technically illegal, in a form that is tolerated but not legalized, as in the case of Thailand and the Philippines.

The popularity of television programs and movies that incorporate sexuality as an element of the story-line points to the acceptance of sexual attitudes that are permissive when compared to the more reserved attitude towards sex outside of marriage that typified the recent past in Western society and which continues in Islamic culture. As a consequence, it is not surprising that sex or romance is, for many tourists, part of the holiday fantasy that may be found in the form of temporary relationships with other tourists or hosts, fulfilled by using commercial sex workers, or be desired but never consummated. For these reasons it is also not surprising that commercial sex industries are found in many tourist destinations.

\section{Thailand's Image as an Erotic Destination}

At an official level the Thai tourism industry has successfully marketed the nation as an exotic destination in both the East and West and has been able to develop a touristic experience that crosses cultural boundaries. The Tourism Authority of Thailand (TAT) has recognized the strength of appeals of the exotic and skilfully used these images to develop a tourism industry that emphasizes Thailand's cultural 
diversity, its scenic beauty, its beaches, wide range of shopping opportunities and culture. TAT reports that it emphatically does not promote Thailand as a sex tourism destination and that it works in conjunction with the Tourist Police to strictly enforce Thailand's anti-prostitution laws. From an official viewpoint the Thailand government has not sought to exploit its image as a destination for erotic experiences through appeals to these images in government funded marketing. Antiprostitution laws were strengthened in 1986 with severe penalties for customers, procurers, brothel owners and even parents (TAT, 2003) but to date this has not led to the cessation of erotic tourism on an industrial scale in Thailand.

Although prostitution is illegal, the image of Thailand as an erotic destination has grown and competes with the exotic as a motivation for travel to Thailand. Much of Thailand's reputation as an erotic destination can be attributed to the notoriety of Thailand as a Vietnam War era (American Phase) R \& R (Rest and Recreation) center for United States troops and other military forces. Clift and Carter (2000) reported that during the $\mathrm{R} \& \mathrm{R}$ era approximately 700,000 US servicemen visited Thailand and their spending in brothels, bars and hotels was estimated to contribute up to 40 percent of Thailand's export income during this period. Following the Vietnam War the red light districts of Bangkok diversified into other markets including commercial sex tours for the European and Japanese markets. In new resort centers such as Pattaya and Phuket, girlie bars and other outlets for prostitution emerged. Reporting of Thailand's sex industry in the media and in travel guides contributed to the development of the image of Thailand as an erotic destination. It is difficult to quantify the impact that these images of the erotic have had on Thailand's marketing of itself as an exotic destination.
In a sense, Thailand's image as an erotic destination has been juxtaposed on the nation's policy of emphasizing the exotic to emerge as a major pull factor for some sectors of the international tourism industry. Thus Patpong, Bangkok's most notorious red light district, is now firmly on the list of the city's tourist attractions, and family groups can be observed shopping in the open-air market that runs the length of the street while touts actively beckon passers-by into strip shows and bars where girls offer "companionship" for a price. As a consequence of the R \& $\mathrm{R}$ era and lax enforcement in following decades, Thailand has gained a reputation as a center for sex tourism, in addition to its long-time and desired status as a generally exotic destination.

The official attitude to the industry is ambiguous, although Lovering (2003) reported that in late 2003 the Thai Justice Ministry issued a proposal to legalize prostitution and register sex workers. Although technically illegal, prostitution continued to flourish in the decades following the Vietnam War era until some of the more obvious establishments were closed in 2002 and during the Asia Pacific Economic Cooperation (APEC) leaders summit held in Bangkok 2003. A number of researchers (del Rosario 1994, Lee, 1991; Richter, 1989) have observed that political leaders have supported tourism-orientated prostitution. Aside from moral judgements on the particulars of the commercial sex industry, it is apparent that any growth of the sex industry, in everyday or in exotic settings such as Thailand, Cambodia, Brazil and the Philippines, generates both positive and negative reactions from tourists, the tourist industry, the host population and the authorities.

Although the Thai sex industry is an unofficial part of the nation's international tourism sector, the industry is not a creation of the international tourism industry but rather 
represents a more traditional response to male sexuality that has a history that considerably pre-dates modern tourism. A number of researchers including Phongpaichit, 1981 (cited in Cohen, 1996) and Truong, 1983 have pointed to the traditional place prostitution has occupied in Thailand. From this domestic base the current internationalized sector of the traditional sex industry has emerged and attracted the interest of foreign customers and researchers. The structure of the industry and its impacts on hosts and guests have been extensively researched (Odzer, 1994; Seabrooke, 1997; Cohen, 1971, 1982; 1986, 1993; Bishop and Robinson 1998; Phillip and Dann 1998) and will not be the subject of more than cursory discussion, given that the aim of the paper is to comment on the impacts that the erotic may have on Thailand's preferred image of the exotic.

\section{Promoting a Sex Tourism Image}

From a positive perspective, the growth of the sex industry has encouraged growth in some inbound tourism market segments, generating employment and contributing to national GDP growth. According to Lovering (2003) the sex industry's contribution may be as high as 3 percent of GDP. This has certainly been the case in Thailand in the past, as noted by Clift and Carter (2000). From a negative perspective, a flourishing trade in erotic tourism can lead to the creation of destination images that might repel some tourist segments, attract other segments of a less desirable nature, create serious public health problems, pose moral concerns and cause increased crime and corruption. Moreover, when the nation's sex industry receives sensationalized coverage, it jeopardizes Thailand's ability to position itself in the marketplace and reduces the positive images that TAT has strived to develop. For example, in a recent report in Time, Perrin (2002, p. 91) writes "Take a stroll into the Sunee Plaza in Pattaya, Thailand, or through Manila's Rajah Sulayman Park, and it's impossible not to notice girls as young as eight painted up like Barbie dolls and openly selling themselves." In another example, in a travel story about Bangkok published in a major Australian newspaper, travel writer Des Houghton (2003, p. 4) remarked, "I suspect that shopping is the engine room that drives the tourist trade- and sex. The city is alive with touts who live off both." Houghton goes on to describe the cost of a two-hour appointment with a sex worker before discussing other attractions, shopping and hotels.

In the long term, the sustainability of Thailand's current dualism of the exotic and erotic as national tourism images is questionable. Many other nations have successfully promoted themselves internationally without recourse to sex tourism while allowing the commercial sex industry to service the domestic and international markets but within strict laws, thereby avoiding the confusion of national images that has emerged as a result of Thailand's sex industry. In some Australian states, brothels have been legalized, and a similar policy of legalization was introduced in New Zealand in 2003. With this type of structure the sexual needs of international tourists can be provided for, but in a manner that avoids the stigma of promoting an image that relies on the erotic as a major attraction. However, a potential problem for a sex tourism industry structured in this manner is that clients may find it more difficult to locate domestic sex workers. Language and uncertainty over where the domestic sex industry is located, particularly if it is organized on a craft structure, may also pose a problem for international tourists. 
Concern over the damage that an uncontrolled sex industry and associated growth in crime can have on national image is not unique to Thailand; other Asian nations face similar problems. Vietnam and Cambodia for example are making positive efforts to create strong cultural destination images, and to assist in this image-building process have introduced strong anti-prostitution measures including the removal of sex tourism centres from public areas. These efforts have had some success in controlling sex tourism in Cambodia, but official corruption in many countries where measures of this nature have been attempted has reduced the effectiveness of control measures.

\section{Managing the Erotic in Thailand's Tourism Industry}

Managing the professional sex industry poses numerous problems for the authorities and is dependent on the successful introduction, enforcement and adjudication of public policies. Community attitudes are also important as they shape public policy and its enforcement. If there is strong public support for legalization or even prohibition of prostitution, public policy has a much higher chance of success than where there is limited public support. In an analysis of the economics of prostitution, Reynolds (1985) outlined four models of control available to the authorities. At one end of the spectrum the Laissez-Faire model describes a commercial sex industry where the government does not interfere and does not attempt to suppress prostitution. The Laissez-Faire model largely describes the current attitude towards the sex industry in Thailand and in part stems from the tolerance of prostitution by Thai society.
The second model identified by Reynolds (1985, p. 39) is described as the control model where "... the legal environment in which prostitution is not only outlawed de jure but it is also penalized de facto". To support this type of legal and enforcement environment, community support is required for suppressing prostitution, perhaps because it is an activity that offends community standards. A number of Islamic nations follow this model.

The third model described by Reynolds is the Regulatory model where various forms of commercial sex are authorized under a licencing system. In the US the State of Nevada has regulations that control brothels, although this regulation is not extended to other forms of prostitution such as "streetwalking" which is technically illegal and therefore not officially sanctioned or licenced, but is tolerated by the authorities. The Regulatory model of control is difficult to achieve and maintain and may not always be a successful policy tool for controlling many aspects of the commercial sex industry. One example of the types of difficulties encountered with the Regulatory model is the exposure of sex slavery practices recently uncovered in Australia where Asian women were enticed into working in legal brothers but had their passports taken and were forced to "repay" various costs such as airfares and accommodation.

The final model described by Reynolds is the Zoning model, which describes a situation where commercial sex industry establishments are located near each other, either voluntarily or through some form of government ordnance. Examples of businesses where this form of control is exercised include adult bookstores, strip shows and brothels. It is possible to envision situations where a mix of these models is applied.

Prostitution is an entrenched feature of the Thai domestic society and anti-prostitution 
laws have proven difficult to enforce because of the lack of community support for measures that will close or suppress the commercial sex industry, particularly that part of the sector which services the foreign market. In part, this is a consequence of the profits that are derived from prostitution that is organized along industrial lines and from the corruption that is associated with the protection of prostitution by elements of the public sector. There are also problems of definition that may impede successful implementation of antiprostitution laws. For example, are bar girls prostitutes in the traditional definition of the word, or are they sex workers operating in the grey zone? As Cohen (1996) reminds us, the sex industry is very "grey" and hard to define, with many "sex workers" and businesses existing on the fringes of an illegal industry legitimized through tolerance but not acceptance.

\section{Possible Options}

Allowing the current situation to continue poses some problems for Thailand. The reaction of tourists to the health problems posed by SARS (Severe Acute Respiratory Syndrome) illustrates the sensitivity of many visitor sectors to health dangers. Thailand continues to have an AIDS problem in spite of a range of measure introduced to combat the disease. While the known rate of HIV infection among commercial sex workers has fallen from 50 percent in 1991 to 20 percent in 2001, there is evidence that HIV prevalence in the commercial sex worker population is increasing in Bangkok and other areas (AVERT, 2003). In the current generally unregulated sex industry there is considerable high potential for customers to become infected with Sexually Transmitted Diseases (STDs) or HIV/AIDS.
Where a tourist acquires HIV/AIDS because of official neglect, perhaps as a result of infected workforce members being allowed to continue working, the government may have to accept some degree of culpability. While not a major issue at present, consumer protection laws in Europe appear to be moving in this direction.

While the risks of AIDS and other STDs do appear to have been greatly reduced in recent years, the demand for erotic tourism may result in a resurgence of the problem in the future. The emergence of the indirect sex market that is outside the control of the authorities has further complicated the situation. According to ADVERT (2003) condom use among indirect sex workers remains low. Moreover, the combined effect of the nation's reputation as a sex tourism center and the potential for foreign visitors to contract HIV/AIDS and other STDs while visiting Thailand can be expected to continue to generate considerable adverse publicity in the future, with the possibility of discouraging other visitor sectors such as the family market.

If the Thai government chooses to allow the current situation to continue, some attention will need to be given to damage control as a consequence of adverse media reports. Regardless of any careful "spin" or sensitive market placement effort and related marketing tactics, fear of real harm can have a catastrophic effect on market share. Incidences of mad cow disease appearing in the human population in the United Kingdom, continental Europe and Japan during the last years of the twentieth century received considerable adverse coverage in the media. The predictable alarm spread among consumers with this news was manifested in noticeable reductions in the demand for a wide range of meat products. In a similar way, negative reporting of cases of HIV/AIDS contracted by visitors to Thailand can be expected to adversely impact on all other 
aspects of Thailand's tourism industry. In a worse-case scenario, Thailand may attract adverse Travel Advisory notices, as occurred during the SARS scare in 2003. Taking a proactive stance should be considered necessary in any well-designed marketing plan.

Zoning of the type found in sex tourism localities such as Nevada and Amsterdam offers a further solution. Zoning may range from official tolerance of a still technically illegal activity to a formal recognition of some or all elements of the commercial sex industry. In Thailand there is evidence of official tolerance of the commercial sex industry aimed at the international market. One example of a de facto zoning system can be found in Chaing Mai where many girlie bars are located along the side streets, discretely away from the main thoroughfares.

De facto zoning of the type found in Chaing Mai may be a solution to the uncontrolled growth and apparent official tolerance of the commercial sex industry in Pattaya, Thailand's first major coastal resort. Girlie bars are located throughout the city's tourism districts, and the workers in these bars are more aggressive in touting for customers compared to Chaing Mai. This contrasts to the situation in the late 1980s when Smith (1992) reported that bars selling sex were located predominantly in the southern end of the resort. Between the extremes represented by Chaing Mai and Pattaya are resorts such as Pukhet which have a significant sex industry based in bars. At the same time, commercial sex establishments are restricted to a small part of the resort, and tourists not wishing to engage in commercial sex can easily avoid the bar district.

Thailand therefore faces a dilemma: does the government enforce existing anti-prostitution laws without significant community support or, alternatively, adopt a policy that recognizes the industry and attempts to control it through some form of regulation including licensing? There are advantages to both approaches, but ultimately it is a task that will be determined by the Thai community and the government that represents the community. Regardless of the outcome, there will need to be some thought given to the possible impacts of the erotic on the preferred tourism image of the exotic.

A decriminalized sex industry may not be a suitable choice for nurturing the long-term sustainability of Thailand's tourism industry. Potential problems include continuing negative images generated by the presence of the industry, public health risk factors that are potentially encountered by international customers, and the social and economic cost placed on the sex worker. Eliminating industrial prostitution would most likely reduce the strength of Thailand's erotic image, allowing it to be replaced by a greater emphasis on the exotic nature of the country. Between these two extremes lies a policy decision that would allow the current position of official tolerance with some enforcement to continue. On the other hand, enforcement of existing legislation may be difficult unless community attitudes change and the opportunities for crime and official corruption are reduced. If existing commercial sex tourism activities are to remain a part of the long-term tourism industry, either in their current illegal form or in some legalized form, there is a need to consider policy alternatives and marketing strategies that will enhance the exotic but hide, at least to some extent, the erotic.

\section{Conclusion}

Sex and sexuality are powerful human emotions. Recognizing the power of sex, the 
mass media has commercialized and exploited sexuality as a marketing tool for an enormous variety of goods and services, many of which have in themselves little to do with matters of human sexuality. Used in this manner, sex becomes an image but not an act where the image and the act are quite separate and understood to be separate by consumers. However, where the use of sex moves from an image to the act, a threshold is crossed and a new set of conditions applies. In the use of the exotic as a destination marketing strategy, sex is often used in an implied sense to develop the notion of a desirable destination. Conversely, in the use of the erotic as the major marketing focus, the imagery moves from implied to actual and a commercial element is introduced.

Ultimately, it is the destination and its society that must determine the form of host/guest relationship that is desired. In Castro's Cuba, prostitution was made illegal and all brothels closed down in 1959 , but by the mid-1990s prostitutes were again on the street, though operating in a very discrete manner and apparently organized along a craft-style structure. The Cuban authorities appear to tolerate this form of prostitution because of its attractiveness to some groups of international visitors. As a consequence, some male and female visitors are attracted to Cuba because of this erotic element of Cuba's tourism industry, but the discretion exercised by visitors and hosts has effectively hidden this element of the nation's tourism industry from cursory view, allowing the authorities to concentrate on other images for the nation.

In the case of Thailand there is some danger that continuing the current dualism will gradually degrade the destination's overall image in the future. It is evident that image capture has occurred in Thailand, although the impact in terms of market segments that desire the exotic rather than the erotic has not been measured. For the authorities, the current industrial nature of the sex industry and apparent lack of community support for more vigorous enforcement against what is an illegal industry creates a number of problems that may be difficult to resolve. While strategies of the nature suggested by Reynolds (1985) provide a range of alternative models, it will ultimately be the community and political leaders that must resolve the dilemma as to the preferred path that future tourism promotion is to take. Understanding and accepting possible consequences of the path taken is an issue that will also need to be considered by all stakeholders in the tourism industry.

For other destinations, use of the erotic as a component of the tourism industry may pose problems for the future as marketers attempt to attract a wider range of tourists. Overt recourse to the erotic may be at the expense of the exotic; however, a more covert use of the erotic, perhaps in the form adopted by Cuba or in specific sex tourism zones, is likely to avert this situation.

\section{References}

Agrusa, J. (2003). AIDS and tourism: a deadly combination. Bauer and McKercher Tourism, Romance, Love and Sex Haworth Hospitality Press, New York.

Agrusa, J. and Prideaux, B. (2002). Tourism and the threat of HIV/AIDS in Vietnam. Asia Pacific Journal of Tourism Research, 7(1), pp. 1-10.

AVERT (2003) The history of the AIDS epidemic in Thailand http://www.avert.org/ visited November 7, 2003.

Bauer, T. \& McKercher, B. (2003). Sex and Tourism: Journeys of Romance, Love and Lust. The Haworth Hospitality Press, New York.

Bishop, R. \& Robinson, L. S. (1998). Night Market: Sexual Cultures and the Thai Economic Miracle. Routledge, London. 
Chen, J. S. \& Hsu, C. H. C.. Measurement of Korea tourists' perceived images of overseas destinations. Journal of Travel Research, 38, pp. 411-416.

Clift, S. \& Carter, S.. Tourism, international travel and sex: themes and research. (pp. 1-22). In S. Clift and S. Carter (eds), Tourism and Sex Culture, Commerce and Coercion. Pinter, London.

Cohen, E. (1971). Arab boys and tourist girls in a mixed Jewish-Arab community. International Journal of Comparative Sociology, 12, pp. 217-233.

Cohen, E. (1982), Thai girls and Farang men: the edge of ambiguity. Annals of Tourism Research, 9, pp. 403-428.

Cohen, E. (1986). Lovelorn Farangs: the correspondence between foreign men and Thai girls. Anthropological Quarterly, 59, pp. 115-127.

Cohen, E. (1988), Tourism and AIDS in Thailand. Annals of Tourism Research, 15, pp. 467-486.

Cohen, E. (1993). Open-ended prostitution as a skilful game of luck: opportunities, risk and security among touristoriented prostitutes in a Bangkok soi. In M. Hitchcock, V. T. King \& M. J. G. Parnwell, Tourism in South-East Asia, pp. 155-178, Routledge, London.

Cohen, E. (1996). Thai Tourism: Hill Tribes, Islands and Open-Ended Prostitution. White Lotus, Bangkok.

Dahles, H. \& Bras, K. (1999). Tourism and Small Entrepreneurs: Development, National Policy, and Entrepreneurial Culture: Indonesian Cases. Cognizant Communication Corporation, New York.

Dann, G. (1977). Anomie ego-enhancement and tourism. Annals of Tourism Research, 17, pp. 155-169.

del Rosario, V. O. (1994). Tourism and Women: The Perspective From Feminist Political Economy. Rethinking Tourism Conference, Bali, August 3-6.

Graburn, N. H. H. (1983). Tourism and prostitution. Annals of Tourism Research, 10, pp. 437-442.

Houghton, D. (2003). In your face. The Courier Mail, Australia, March 29, p. 4.

Hubbard, P. (2003). In the border-zone. Cultural Geographies, 10, pp. 112-119.

LaPage, W. F. \& Cormier, P. I. (1977). Images of camping barriers to participation. Journal of Travel Research, 15 (Spring), p. 21.

Lee, W. (1991). Prostitution and tourism in South-East Asia. In N. Redclift \& M. T. Sinclair, Working Women: International Perspectives on Labour and Gender Ideology. Routledge, London.

Leheny, D. (1995). A political economy of Asian sex tourism. Annals of Tourism Research, 14, pp. 367-384.
Lovering, D. (2003). Thailand mulls legalizing prostitution. The Honolulu Advertiser, November 26, p. A9.

Minca, C. (2000). The Bali Syndrome: the explosion and implosion of "exotic" tourism spaces. Tourism Geographies, 2(4), pp. 389-403.

Odzer, C. (1994). Patpong Sisters. Arcade Publishing, New York.

Office of Communicable Disease Control Region 10, Chiang Mai, Thailand. (1999). AIDS Prevention and Control in Upper Northern Part of Thailand. Chiang Mai, Thailand.

Oppermann, M. (1998). Sex Tourism and Prostitution: Aspects of Leisure, Recreation, and Work. Cognizant Communication Corporation, New York.

Pearsall, J. (2002). Concise Oxford English Dictionary, 10th edn. Oxford University Press, Oxford.

Perrin, A. (2002). Shame: Asia's child sex industry is booming despite tougher laws and a few high profile deportations. Time, September 2, pp. 18-19.

Phillip, J. \& Dann, G. (1998). Bar girls in ventral Bangkok: prostitution as entrepreneurship. In M. Opperman (ed.), Sex Tourism and Prostitution: Aspects of Leisure, Recreation and Work, pp. 60-70. Cognizant Communication Corporation, New York.

Phongpaichit, P. (1981). Bangkok masseuses: holding up the family sky. South East Asian Chronicle, 78, pp. 15-23.

Prideaux, B. (1995). Effects of crime on the tourism industry: a study of Queensland and beach resorts. In F. Go, W. Theodald \& H. I. Qu (eds). Reducing the Barriers to International Tourism, Proceedings of International Tourism Symposium, The Hong Kong Polytechnic University, Beijing, pp. 147-166.

Pruitt, S. \& La Font, S. For love and money: romance tourism in Jamaica. Annals of Tourism Research, 22, pp. $422-440$.

Reynolds, H. (1985). The Economics of Prostitution, Charles C. Thomas Publisher, Springfield.

Richter, L. K. (1989). The Politics of Tourism in Asia. University of Hawaii Press, Honolulu.

Ryan, C. (2000). Tourism and Sex: Culture, Commerce, and Coercion. In S. Clift \& S. Carter (eds), Tourism and Sex Culture, Commerce and Coercion. Pinter, London.

Ryan, C. \& Hall, C. M. Sex Tourism, London, Routledge. Seabrooke, J. Travels in the Skin Trade: Tourism and the Sex Industry. Pluto Press, London.

Smith, R. A. (1992). Beach resort evolution. Annals of Tourism Research, 19(2), pp. 304-322. 
Symanski, R. (1981). The Immoral Landscape: Female Prostitution in Western Societies. Butterworth, Toronto.

Tapachai, N. \& Waryszak, R. (2000). An examination of the role of beneficial image in tourist destination selection, Journal of Travel Research, 39, pp. 37-44.

TAT (2003), TAT supports fight against child prostitution, http://www.tat.or.th/visitor/child_pros.htm, visited October 20, 2003.
Thiemann, H. (1989). Reisende Maenner: Sextourismus als spezielle form der okologischen zerstoerung - Das Beispiel Thailand. In C. Euler, (ed.), Eingeborene - ausgebucht: Okologische Zerstorung durch Tourismus, pp. 91-103. Focus Verlag, Giessen.

Um, S. \& Compton, J. L. (1992). The role of perceived inhibitors and facilities in pleasure travel destination decisions. Journal of Travel Research, 30(3), pp. 18-25. 